\title{
Three Different Ways to Miss a Granulosa Cell Tumor - A Lesson to be Learned
}

\author{
Neethu Puthalon Kunnath, Sony Nanda, Janmejaya Mohapatra
}

Department of Gynecological Oncology AHPGIC, India.

\begin{abstract}
Granulosa cell tumours (GCTs) account for approximately $70 \%$ of malignant sex-cord stromal tumors but are still uncommon and comprise only $2-5 \%$ of all ovarian neoplasms. They are classified as adult and juvenile GCTs. These are often low grade malignancies and are usually diagnosed in early stages, but with an potential for late recurrence. Case 1: A 51-year woman with c/o PMB with biopsy showing endometrial polyp. She underwent a total abdominal hysterectomy and a bilateral salpingo-oophorectomy (TAH BSO) with omental biopsy after intraoperative pathology confirmation of a Adult granulosa cell tumor (AGCT) of the ovary. She had a good post-operative recovery and was advised for regular and long term follow up. Case 2: A 63-year woman c/o PMB with an adult granulosa cell tumor that initially presented as endometrial hyperplasia on biopsy. She underwent a TAH BSO and omental biopsy after intraop frozen section confirmed of AGCT of the ovary. She had an uneventful post-operative recovery. Case 3: A 68-year woman with an AGCT that was initially treated as endometrial carcinoma. She underwent a Comprehensive Surgical Staging due to initial misdiagnosis of endometrial carcinoma. Her final biopsy report showed it to be a granulosa cell tumor of the ovary and adenocarcinoma of the endometrium. She had a good post-operative recovery and is being followed up till now. The multifaceted presentations with its erratic biological behaviour coupled with late recurrences are diagnostic pitfalls necessitating a high degree of suspicion for accurate clinical diagnosis.
\end{abstract}

Keywords: Adult Granulosa Cell Tumor- Juvenile Granulosa Cell Tumor- Post menopausal bleeding- endometrium- TAH BSO

Asian Pac J Cancer Care, 6 (3), 345-348

\section{Introduction}

Granulosa cell tumours (GCTs) comprise of nearly $70 \%$ of malignant stromal tumors but are still uncommon and account for only $2-5 \%$ of all ovarian neoplasms. These tumours originate from hormonally active granulosa cells which lie in close association with the ovarian oocytes and are responsible for estradiol production [1]. Based on there clinicopathological characteristics they are classified as adult (AGCTs) and juvenile (JGCTs). AGCTs account for approximately $1 \%$ to $2 \%$ of all ovarian tumors and $95 \%$ of all GCTs [2] AGCTs (95\%) almost always occur in postmenopausal women while JGCTs $(5 \%)$ are diagnosed under 30 years of age and maybe seen in prepubertal girls in 5\% of cases [3]. These are often low grade malignancies and are usually diagnosed in early stages, but with an awkward biological potential for late
Submission Date: 05/27/2021 Acceptance Date: 07/03/2021

\footnotetext{
Corresponding Author:

Dr. Sony Nanda

Department Department of Gynecological Oncology AHPGIC, India.

Email: sony.nanda@gmail.com
} 
free and non tender. USG was done which showed a bulky uterus of $16^{*} 11^{*} 7 \mathrm{~cm}$ with right ovary $3 * 1.8 \mathrm{~cm}$ and left ovary of $2.7^{*} 1.7 \mathrm{~cm}$. Heterogeneous hypoechoic lesion $(9 * 6 \mathrm{~cm})$ with internal vascularity noted in endometrial cavity with possible myometrial invasion. CECT Pelvis report showed enlarged uterus $\left(16^{*} 11 * 8 \mathrm{~cm}\right)$ and normal enhancement pattern, endometrium appeared thickened $(48 \mathrm{~mm})$ and irregular. $\mathrm{B} / \mathrm{L}$ ovaries normal in shape size and enhancement pattern (Figure 1A, B, C). CA 125 was normal. Diagnostic hysteroscopy with endometrial biopsy (DH EB) was done. Histopathology report (HPR) showed endometrial polyp. She was planned for Laparotomy, intraoperative pathology and accordingly to proceed. On opening the abdomen uterus was bulky of 18 weeks size with normal looking ovaries. Cut section (C.S) of uterus showed entire uterine cavity to be covered with polypoidal growth. Intraoperative pathology showed it to be complex endometrial hyperplasia with focal nuclear atypia. Total abdominal hysterectomy with bilateral salpingoophorectomy (TAH BSO) with omental biopsy and sentinel lymph node biopsy done (Figure 2A, B, C). Her final histopathology report (HPR) showed benign endometrial polyp in uterine cavity and confirmed the presence of AGCT of low grade histologic type in right ovary (Figure 3A,B). Her postoperative period was uneventful and was discharged with the advice of regular follow up. After her final HPR she was advised to do s.inhibin which was $4.60 \mathrm{pg} / \mathrm{ml}$.

\section{Case 2}

63 years old postmenopausal women P4L4, both FTND presented to our hospital with c/o PMB since
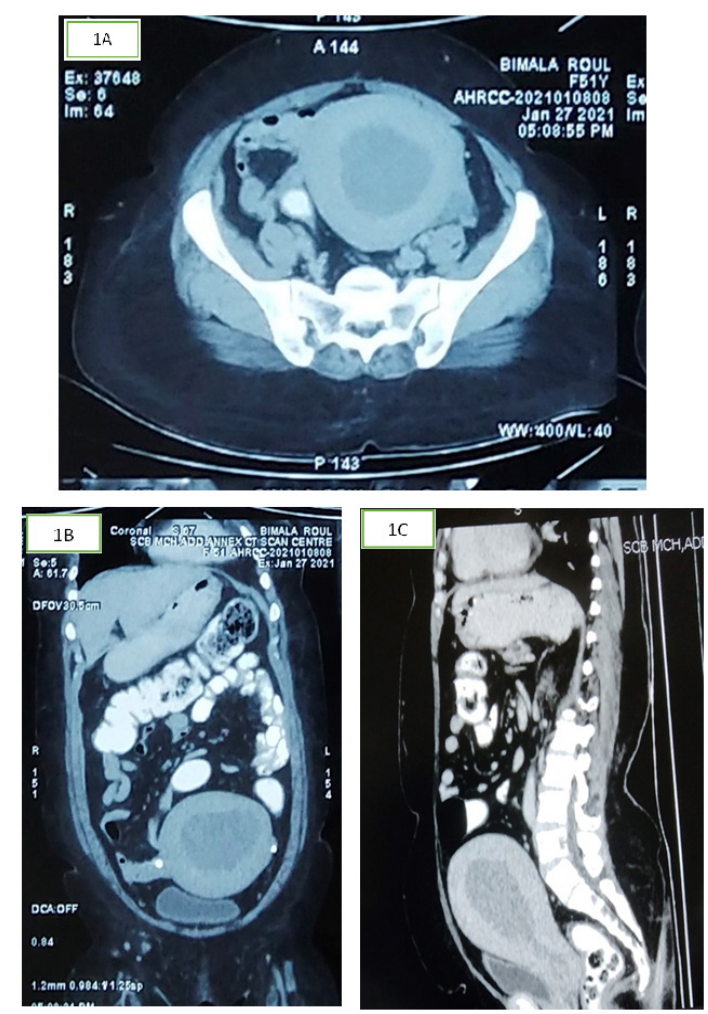

Figure 1. (A,B,C)-CECT
1 month with heavy bleeding since 3 days. She has attained menopause $15 y$ rs back. On examination, she had tachycardia (P.R.-103/min) and her blood pressure was recorded as $110 / 70 \mathrm{~mm} \mathrm{Hg}$, P.A examination revealed a soft and non tender abdomen. Per speculum examination showed cervix flushed with vagina. Bleeding through os was present. On P.V examination uterus was normal size, midposition, $b / 1$ fornices were free. MRI report showed a bulky uterus with expanded irregular endometrial lining being merged along the myo-endo junction. Endometrium shows asymmetric thickening (15 to $18 \mathrm{~mm}$ ). Parametrium normal, b/l ovaries atrophied.

DH EB done. Hysteroscopic findings showed anterior endometrial polypoidal growth $(3 * 3 \mathrm{~cm})$ with large vessels. Her HPR showed disordered proliferative endometrium, without any evidence of malignancy or hyperplasia .

Her CA 125 report and other hormonal profile were normal. Patient was taken up for laparotomy where TAH BSO with omental biopsy was done. Gross specimen showed bulky uterus with normal right sided ovary and enlarged left ovary. C.S showed polypoidal growth of $3 * 3 \mathrm{~cm}$ seen in endometrial cavity, left ovary showed a solid cystic area of $3 * 2 \mathrm{~cm}$ ( Figure 2D). Intraoperative pathology showed endometrial polyp in the endometrial cavity and left ovary showed sex cord stromal tumour (granulosa tumor). Her final HP picture of left ovary showed features of AGCT such as some cells showing grooved nuclei (coffee bean nucleus) and call exner bodies with average mitotic activity of 5-6/10hpf, capsule was uninvolved by tumour. Uterus showed adenomyosis and endometrial cavity showed presence of benign endometrial polyp. Right adnexa and omentum was free of tumour. Two weeks post operatively s.inhibin was done which was $9.8 \mathrm{pg} / \mathrm{ml}$.

Thus, the final diagnosis of AGCT of the left ovary stage I A was made. Patient had an uneventful postoperative recovery. Patient went home on $8^{\text {th }}$ postoperative day with an advice to come for regular follow-up.

\section{Case 3}

A 68 years woman, P2L2, was referred to our hospital from a peripheral hospital with complaints of PMB of 2 months duration, lower abdominal pain of 5 days. She attained menopause 20 years before. Upon clinical examination, she was found to be moderately built, ECOG 0, with pallor. Other systems were normal. $\mathrm{P} / \mathrm{A}$ examination, there was no evidence of tenderness, mass or free fluid. P.V examination showed a bulky uterus, with a left adnexal mass of $8 * 8 \mathrm{~cm}$ with restricted mobility, right fornix appeared free.

Her laboratory investigations revealed mild neutrophilic leukocytosis, normal liver and kidney functions with serum CA-125 of $17.37 \mathrm{u} / \mathrm{ml}$ and CEA of $6.73 \mathrm{ng} / \mathrm{ml}$. USG with Doppler done which showed solid adnexal mass with dominant arterial flow with low resistance flow, uterus was bulky with thick irregular endometrium. CECT pelvis showed poorly circumscribed heterogeneous solid/cystic adnexal lesion of $11 * 9 * 8 \mathrm{~cm}$, bulky uterus with thick endometrium. Few subcentimetric aortocaval nodes seen. DH EB showed grade 2 endometrioid adenocarcinoma. 

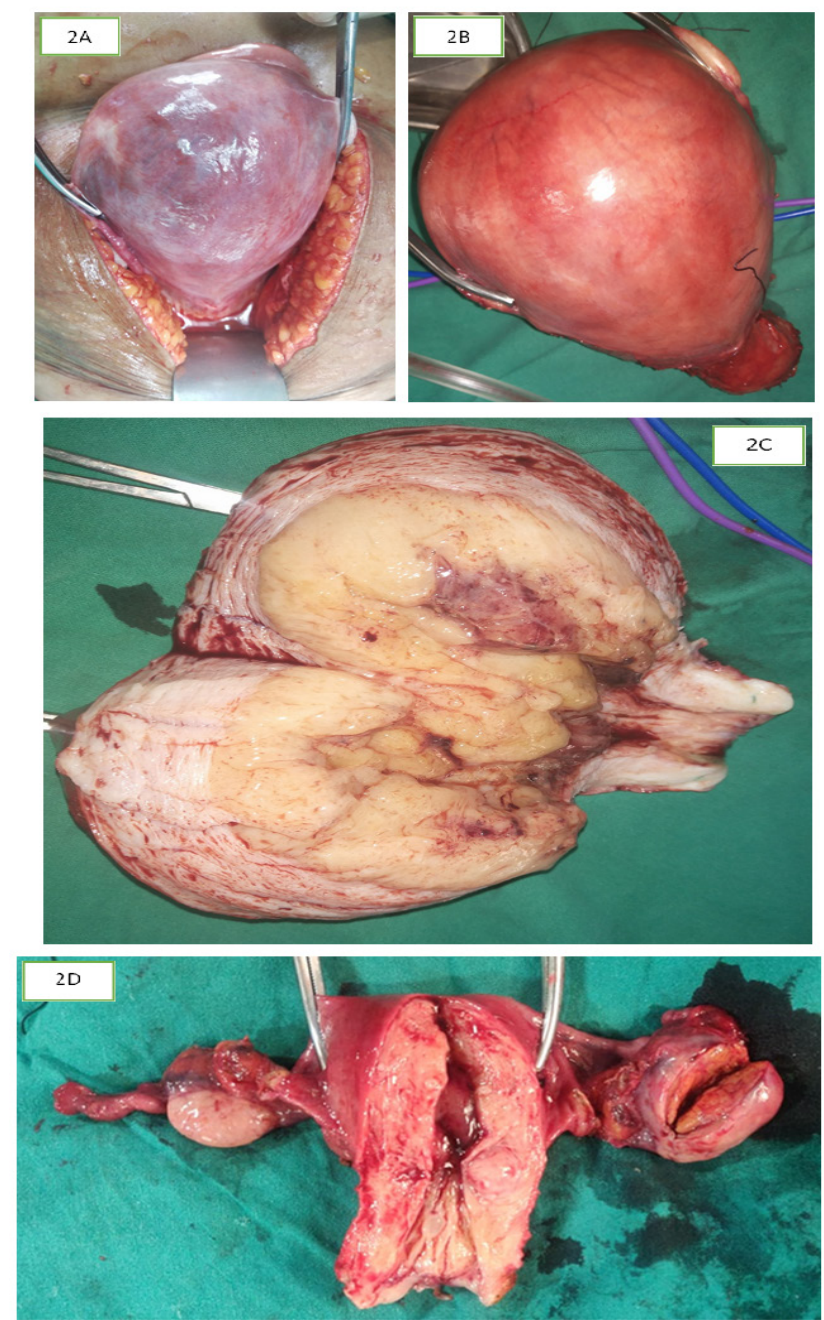

Figure 2. (A,B,C,D)-GROSS PICTURES

Comprehensive surgical staging was planned suspecting it to be a case of Ca endometrium. Type 2 Radical hysterectomy with bilateral pelvic lymph node dissection with paraortic lymph node dissection with infracolic omentectomy was done. On C.S uterus was 10-12 weeks size with a growth of $2 \mathrm{~cm}$ with less than $50 \%$ myoinvasion. Left ovary was $10 * 10 \mathrm{~cm}$. Intraoperative pathology showed sex cord stromal tumor in left ovary. Her final histopathology report showed left ovarian AGCT, ovarian capsule uninvolved by tumor, mitoses $3 / 10 \mathrm{hpf}, \mathrm{b} / \mathrm{l}$ tubes uninvolved by tumor. Uterus showed endometrial adenocarcinoma of endometriod type, architectural grade 1 , nuclear grade 2, myoinvasion less than $50 \%$, LVSI negative, omentum free, lymph nodes were negative. Her post operative period was uneventful. She is on regular follow up with us till now and is doing well.

\section{Discussion}

GCTs were first described in 1855 by Rokitansky as chronicled in Chew et al.'s manuscript. Presently, little is known regarding the molecular and genetic

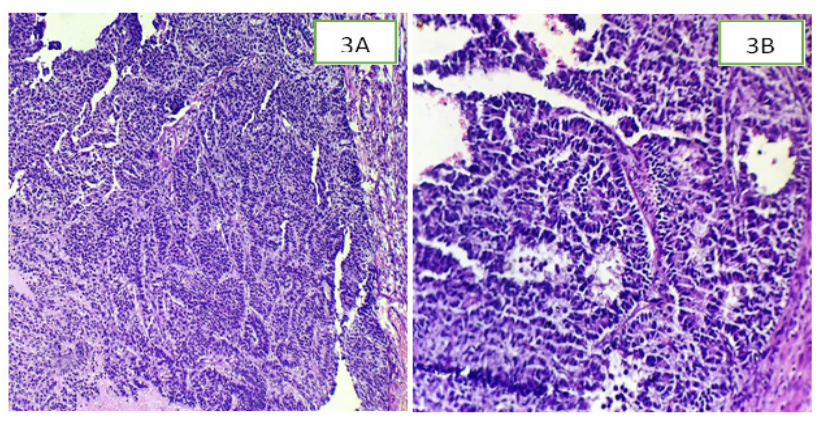

Figure 3. (A,B)-Histology 
changes associated with GCTs. $>90 \%$ of adult GCT's have a missense somatic C134Wmutation in the FOXL2 gene and have been associated with a variety of genetic abnormalities such as trisomy 12/14, monosomy 22 [1]. Patient's age \& disease extent are taken into account while deciding on treatment. Usually, only surgery is adequate primary treatment. Standard surgical treatment of ovarian AGCTs has changed over the years. Recently published literature suggested a lack of lymph node involvement and omission of the lymphadenectomy as part of the primary surgical staging of these tumors was advocated [4]. A unilateral salpingo-oophorectomy is appropriate therapy for stage IA tumors in reproductive age group. An endometrial biopsy should be performed to rule out the possibility of a coexistent endometrial adenoacinoma. For perimenopausal and postmenopausal women, only TAH BSO is sufficient [3]. For the use of adjuvant radiotherapy, controversial results exists. Although some studies have shown irradiation to be beneficial in recurrent, metastatic or as adjuvant treatment postoperatively, there are no randomized study assessing its role [5-8]. The main indications for chemotherapy in early stage GCT patients are large tumors with high mitotic activity or breached capsule [4].

The multifaceted presentations with its erratic biological behaviour coupled with late recurrences are diagnostic pitfalls necessitating a high degree of suspicion for accurate clinical diagnosis. Even in our case series we did not suspect the cause of PMB to be GCT due to its rarity and atypical presentation. In our first 2 reports b/l ovaries were normal both clinically and radiologically but final HPR showed GCT which proved to be a diagnostic dilemma for us .

In conclusion, Lack of evidence based predictive and prognostic factors deters the accurate prediction of the biological behavior of individual GCTs. However, lifelong follow up including physical examination, imaging, and tumor markers is recommended for patients with GCTs as late recurrences beyond 5 years are characteristic of this disease.

\section{References}

1. Kanthan R, Senger J, Kanthan S. The Multifaceted Granulosa Cell Tumours-Myths and Realities: A Review. ISRN Obstetrics and Gynecology. 201209 13;2012:1-12. https:// doi.org/10.5402/2012/878635

2. Ukah CO, Ikpeze OC, Eleje GU, Eke AC. Adult granulosa cell tumor associated with endometrial carcinoma: a case report. Journal of Medical Case Reports. 201108 02;5(1). https://doi.org/10.1186/1752-1947-5-340

3. Rudra S, et al. Int J Reprod Contracept Obstet Gynecol. 2020. $2020 \mathrm{Feb} ; 9(2): 835-8$.

4. Bacalbasa N, Stoica C, Popa I, Mirea G, Balescu I. Endometrial carcinoma associated with ovarian granulosa cell tumors-a case report. Anticancer research. 2015 Oct 1;35(10):5547-50.

5. Björkholm E, Silfverswärd C. Prognostic factors in granulosacell tumors. Gynecologic Oncology. 1981 06;11(3):261-274. https://doi.org/10.1016/0090-8258(81)90040-8

6. Evans AI, Gaffey T, Malkasian Jr G, Annegers J. Clinicopathologic review of 118 granulosa and 82 theca cell tumors. Obstet Gynecol. 1980;55:231-8.
7. Schwartz PE, Smith JP. Treatment of ovarian stromal tumors. American Journal of Obstetrics and Gynecology. 1976 06;125(3):402-411. https://doi.org/10.1016/00029378(76)90577-9

8. Diddle AW. Granulosa- and theca-cell ovarian tumors: Prognosis. Cancer. 1952 03;5(2):215-228. https:// doi.org/10.1002/1097-0142(195203)5:2<215::aidcncr2820050203>3.0.co;2-o

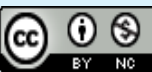

This work is licensed under a Creative Commons AttributionNon Commercial 4.0 International License. 